\title{
CARACTERIZAÇÃO DE EVENTOS EXTREMOS DO NÍVEL DO MAR EM SANTOS E SUA CORRESPONDÊNCIA COM AS REANÁLISES DO MODELO DO NCEP NO SUDOESTE DO ATLÂNTICO SUL
}

\author{
RICARDO MARTINS CAMPOS ${ }^{1}$, RICARDO DE CAMARGO² E JOSEPH HARARI ${ }^{3}$ \\ ${ }^{1}$ Centro de Engenharia e Tecnologia Naval (CENTEC), Instituto Superior Técnico, \\ Universidade Técnica de Lisboa, Portugal \\ ${ }^{2}$ Depto. Ciências Atmosféricas do Instituto/Universidade de São Paulo (IAG/USP), SP \\ ${ }^{3}$ Depto. Oceanografia Física, Química e Geológica (IO/USP), SP 05508-900. \\ riwave@gmail.com,ricamarg@model.iag.usp.br, joharari@usp.br
}

Recebido Março 2009 - Aceito Setembro 2009

\begin{abstract}
RESUMO
Este trabalho tem como objetivo identificar a influência atmosférica em escala sinótica sobre o oceano, para eventos extremos de maré meteorológica na costa sudeste brasileira. Para isso foram utilizados dados de elevação do nível do mar do Porto de Santos-SP, campos de vento e pressão em superfície das reanálises do modelo do NCEP abrangendo o Atlântico Sul, no período de 1951 a 1990. Foi possível identificar a variabilidade sazonal e o padrão de evolução dos sistemas atmosféricos associados aos eventos extremos, de grande relevância para aplicações em prognósticos e alertas a autoridades. O outono e inverno apresentaram a maior ocorrência de extremos positivos (40,2 \% e $30,8 \%$ respectivamente), enquanto a primavera e o inverno foram as estações com maior número de extremos negativos (47,2 \% e 32,3 \% respectivamente). Os resultados mostram que os casos mais importantes de sobre-elevação do nível do mar ocorrem com a evolução e persistência de sistemas de baixa pressão sobre o oceano, com ventos de sudoeste acima de $8 \mathrm{~m} / \mathrm{s}$, juntamente com o anticiclone da retaguarda posicionado sobre o continente.
\end{abstract}

Palavras-Chave: Ressacas, Análise Sinótica, Santos (SP, Brasil)

\begin{abstract}
CHARACTERIZATION OF EXTREME SEA LEVEL EVENTS IN SANTOS AND THEIR CORRESPONDENCE WITH THE NCEP MODEL REANALYSIS IN THE SOUTHWEST OF THE SOUTH ATLANTIC.

This work aims to identify the synoptic scale atmospheric influence over the ocean for extreme events of storm surges events in the Southeastern Brazilian coast. Time series of sea surface height at the Port of Santos as well as wind and surface pressure from the NCEP reanalysis model enclosing the South Atlantic, for period 1951-1990, were used. Seasonal variability and typical evolution of atmospheric systems were found to be associated with extreme events, very relevant for applications on prognostics and warnings to authorities. Autumn and winter are seasons with the highest occurrence of positive extreme events ( $40.2 \%$ and $30.8 \%$ respectively) and the spring and winter are the ones with negative extreme events (47.2 \% and $32.3 \%$ respectively). The results show that the storm surges events depend on low pressure systems development and persistence over the ocean, with southwesterly winds over $8 \mathrm{~m} / \mathrm{s}$, together with a continental anticyclone presence.
\end{abstract}

Keywords: Storm Surges, Synoptic Analysis, Santos (SP, Brazil). 


\section{INTRODUÇÃO}

O nível do mar é continuamente modificado positiva ou negativamente pela atmosfera. A diferença entre a maré observada e a maré astronômica prevista para determinado local, quantifica a influência desse tipo de fenômeno sobre a orla continental, sendo definida como maré meteorológica (Pugh, 1987). No espectro, as marés meteorológicas possuem períodos da ordem de alguns dias. Espacialmente, as pistas de atuação do vento associadas aos casos mais extremos de sobre-elevação, possuem extensão da ordem de centenas de quilômetros.

A importância relativa dos movimentos de maré astronômica e maré meteorológica depende da época do ano e da batimetria local. No entanto, se pode afirmar que, em geral, distúrbios meteorológicos são mais intensos no inverno e possuem maior efeito em águas rasas (Camargo e Harari, 1994). O nível do mar pode se elevar extraordinariamente causando inundações na costa, quando tempestades severas, agindo em águas litorâneas, ocorrem durante períodos de máxima maré astronômica (sizígia). Regiões costeiras com baixo relevo e densamente povoadas podem vir a sofrer desastres na presença de anomalias oceânicas. Da mesma forma, grandes oscilações negativas do nível médio do mar são altamente indesejáveis para a navegação de grande porte, nas quais os procedimentos de acesso e atracação ficam mais difíceis e arriscados, por vezes impossibilitando as operações.

Um exemplo que ilustra o problema é mostrado na Figura 1, onde uma frente fria gerou grandes ondas e elevação do nível do mar em Junho de 2005 em Santos. O evento causou a destruição de parte do calçamento e jardim da praia, problema que se repete por diversos anos em algumas cidades do litoral sul e sudeste do Brasil. O planejamento de obras costeiras, operações portuárias, atividades petrolíferas envolvendo navios e plataformas, esportes ligados ao mar, entre outros, são exemplos de atividades que podem se beneficiar diretamente

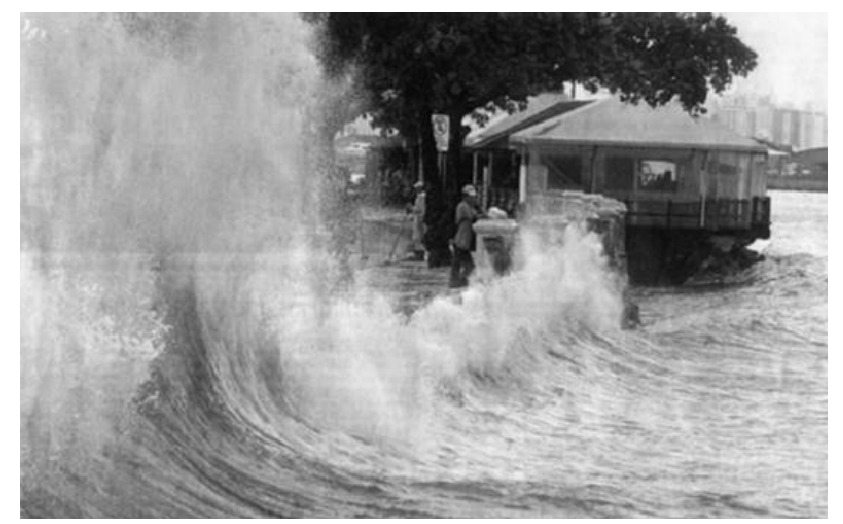

desse tipo de estudo. No sudeste brasileiro, área de foco desse trabalho, o nível do mar responde constantemente às forçantes atmosféricas, motivando o estudo sinótico e climatológico envolvendo os eventos de maré meteorológica.

Existem alguns trabalhos que enfocam este tipo de fenômeno no Brasil. Stech e Lorenzzetti (1992), com base em resultados de modelo numérico, analisaram a resposta da plataforma sudeste brasileira à passagem de frentes frias de inverno e propõem um modelo conceitual de variação espaçotemporal do campo de vento nestas condições. Camargo e Harari (1994) apresentaram dois estudos de casos de intensa influência meteorológica sobre a plataforma continental, também através da utilização de modelo numérico hidrodinâmico, superpondo as oscilações sub-tidais às nove principais componentes de maré da região.

Marone e Camargo (1994) analisaram um evento de sobre-elevação do nível médio do mar em Paranaguá, com a identificação de um intenso sistema frontal sobre o oceano, porém com pouca influência sobre o continente. Castro e Lee (1995) utilizaram registros simultâneos de nível do mar, pressão atmosférica e vento em estações costeiras na plataforma sulsudeste e analisaram as oscilações sub-tidais, que caracterizam a resposta oceânica às influências meteorológicas. Estes autores identificaram bandas de frequências energéticas entre 3 e 10 dias associadas às forçantes meteorológicas, assim como, padrões de propagação de distúrbios do nível médio do mar ao longo da costa sul-sudeste. Mais recentemente, Oliveira et. al. (2006) estudaram a variabilidade do nível do mar observado na Baía de Paranaguá-PR, e fizeram predições dessas influências, inerente às condições atmosféricas, utilizando um modelo de Rede Neural. Os resultados sugerem a utilização do modelo como complemento à previsão de maré baseada no método das constantes harmônicas.

Abordagens observacionais e numéricas, sobre as marés meteorológicas em outras regiões do globo, evidenciam

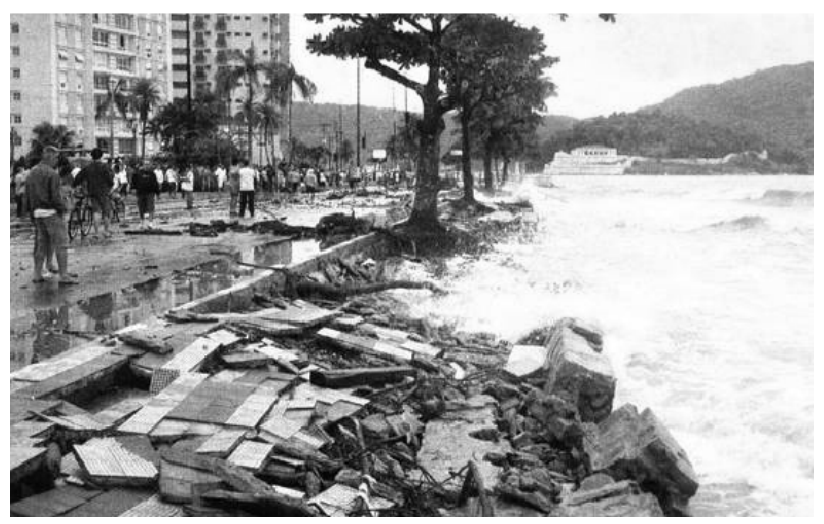

Figura 1 - Destruição da calçada da Avenida Bartolomeu de Gusmão, na Ponta da Praia em Santos-SP, durante ressaca ocorrida em Junho de 2005. 
a relevância deste fenômeno. Já na década de 60, Pore (1964) analisou a relação do vento e da pressão em tempestades extratropicais na formação de grandes marés meteorológicas em Atlantic City - Estados Unidos. O trabalho tem a intenção de fornecer equações empíricas, que possibilitem a previsão do fenômeno, e destaca que a abrangência espacial ao longo da costa é mais importante para o empilhamento do que o vento local. Peng et. al. (2006) estudaram as grandes marés meteorológicas e inundações geradas por furacões nos Estados Unidos, e apontam o papel importante do posicionamento da pista, da trajetória e do ângulo de incidência da tempestade na região costeira. Dong et. al. (2006) estudaram os eventos negativos de maré metorológica na costa de Qingdao - China. O trabalho aborda as variações sazonais, os processos meteorológicos geradores dos eventos e realiza uma análise de extremos com a técnica Peaks Over Threshold.

Ullmann et. al. (2007) pesquisaram as variações temporais do nível do mar e sua elevação associada ao vento em superfície em Camargue-França, utilizando dados de 1975 a 1995. O trabalho aponta uma taxa de crescimento de 4 milímetros ao ano, devido ao aumento na intensidade dos ventos com direções entre $100^{\circ}$ e $120^{\circ}$. Fiore et. al. (2009) estudaram os efeitos costeiros das marés meteorológicas em Mar Del Plata - Argentina de 1956 a 2005. A abordagem envolveu intensidade, duração e frequência dos fenômenos. Foi encontrado aumento no número médio de eventos por década, na altura dos eventos positivos e na duração dos eventos. As duas últimas décadas apresentaram média de 8 centímetros superior às duas primeiras, e 2 horas a mais na duração dos casos. Butler et. al. (2007) analisaram mudanças na severidade das marés meteorológicas no Mar do Norte entre 1955 e 2000. O trabalho mostra fortes tendências positivas na frequência e intensidade dos eventos na porção nordeste do mar. Ao contrário de Fiore et al. (2009) e Butler et. al. (2006), Raicich (2003) encontrou pequena diminuição na ocorrência de eventos extremos positivos e negativos de nível do mar entre 1939 e 2001 em Trieste, ao norte do Mar Adriático.

Motivado pelas questões apresentadas anteriormente, o presente trabalho desenvolve-se baseado em dois objetivos:

1) Quantificar e analisar a ocorrência de eventos extremos positivos e negativos de maré meteorológica, focando as variações sazonais e interdecadais.

2) Conhecer o quadro sinótico e a evolução dos sistemas atmosféricos geradores de tais extremos.

\section{MATERIAL E MÉTODOS}

O conjunto de dados utilizados consiste em elevações horárias do nível do mar em Santos, de 00Z de 1/1/1951 a $23 Z$ 31/12/1990, e campos de pressão atmosférica e vento em superfície no Atlântico Sul abrangendo o mesmo período, porém em médias diárias, na grade de $90^{\circ} \mathrm{W}$ a $0^{\circ}, 70^{\circ} \mathrm{S}$ a $0^{\circ}$; com resolução $1,8750^{\circ} \mathrm{em}$ longitude por $1,9045^{\circ} \mathrm{em}$ latitude, fornecidos pelo National Center for Environmental Prediction - NCEP (Kalnay et al., 1996). Apesar de constituir uma longa série temporal, infelizmente não se dispõe de registros mais recentes desta mesma estação maregráfica.

Os dados de elevação do nível do mar em Santos foram submetidos ao filtro de Lanczos passa-baixa no domínio do tempo, com frequência de corte de 28 horas. Esse procedimento permite eliminar quase totalmente a influência das forçantes astronômicas, uma vez que as principais componentes possuem períodos em torno de 8 e 24 horas, as quais são descritas em Harari e Camargo (1994).

Com o objetivo de analisar cada uma das décadas, o período de 40 anos de dados foi dividido em quatro, obtendo-se arquivos individuais de 10 anos cada um, que foram submetidos a uma metodologia única. As séries filtradas de nível do mar foram também divididas de acordo com as estações do ano, seguindo a seguinte definição: verão - meses de dezembro, janeiro e fevereiro; outono - meses de março, abril e maio; inverno - meses de junho, julho e agosto; primavera - meses de setembro, outubro e novembro. Em seguida foram selecionados apenas os casos estatisticamente independentes com elevações do nível médio do mar superiores a +2 desvios-padrão $(+0,38$ metros) e inferiores a -2 desvios-padrão (-0,38 metros), separando-se assim eventos máximos e mínimos (vide exemplo na Figura 2). Finalmente foi realizada a quantificação desses casos para as quatro décadas.

\subsection{Composições de Pressão e Vento em Superfície Utilizando Dois Desvios-Padrão}

A construção das composições se inicia com a seleção de valores da série filtrada acima e abaixo de +2 e -2 desvios-padrão, respectivamente. Os períodos correspondentes foram utilizados para selecionar os dados simultâneos nos arquivos de pressão e vento em superfície, gerando arquivos sazonais com os índices dos extremos de maré meteorológica diários. As composições finais foram então obtidas através de médias simples dos casos individuais associados aos dois conjuntos, envolvendo os extremos positivos e negativos de maré meteorológica. Em outras palavras, buscou-se obter um padrão sinótico típico relacionado a estes eventos através de médias temporais dos campos de pressão e componentes zonal e meridional do vento em superfície, para os dias em que ocorreram casos extremos de maré meteorológica. Esse procedimento foi realizado para cada década, mas como as variações dos quadros sinóticos associados são muito pequenas, serão expostos apenas os resultados para a série total. 


\subsection{Evolução Temporal do Quadro Sinótico Associado a Extremos de Maré Meteorológica}

Nesta etapa a metodologia constitui-se basicamente na construção de composições com os campos de vento e pressão em superfície, para situações de nível médio do mar acima e abaixo de +3 e -3 desvios-padrão. Em seguida, realiza-se o mesmo procedimento para os dois dias anteriores a cada evento extremo. Dessa forma, a seqüência das composições permite analisar a evolução típica de sistemas causadores de grandes ressacas em Santos, e em boa parte do litoral sudeste do Brasil.

\section{RESULTADOS E DISCUSSÕES}

Inicialmente são apresentadas as tabelas das ocorrências dos eventos superiores e inferiores a 2 desvios-padrão e as distribuições relativas à estatística inicial da série completa. Pode-se notar nas Tabelas 1 e 2, que o padrão principal de cada estação se mantém relativamente constante. Para eventos de sobre-elevação do nível do mar a ocorrência média é de $14,5 \%$ na primavera, $13,4 \%$ no verão, $40,2 \%$ no outono e $30,8 \%$ no inverno. As ocorrências de subelevação têm média de 47,2 \% na primavera, $10,4 \%$ no verão, $10,0 \%$ no outono e $32,3 \%$ no inverno.

Os períodos mais anômalos foram os invernos de 1951 a 1960 , que apresentaram poucos valores acima de +2 desvios-padrão, com 26,9 \% em relação ao total da década, e as primaveras de 1971 a 1980, com grandes quantidades de casos abaixo de -2 desvios-padrão, com $60,0 \%$ do total da década. Outra feição evidente nos resultados é a tendência do outono ter, em geral, muitos eventos acima de +2 desvios-padrão e poucos abaixo de -2 desvios-padrão (40,2 \% e 10,0 \% respectivamente). Em contraponto, a primavera apresenta muitos casos de elevação

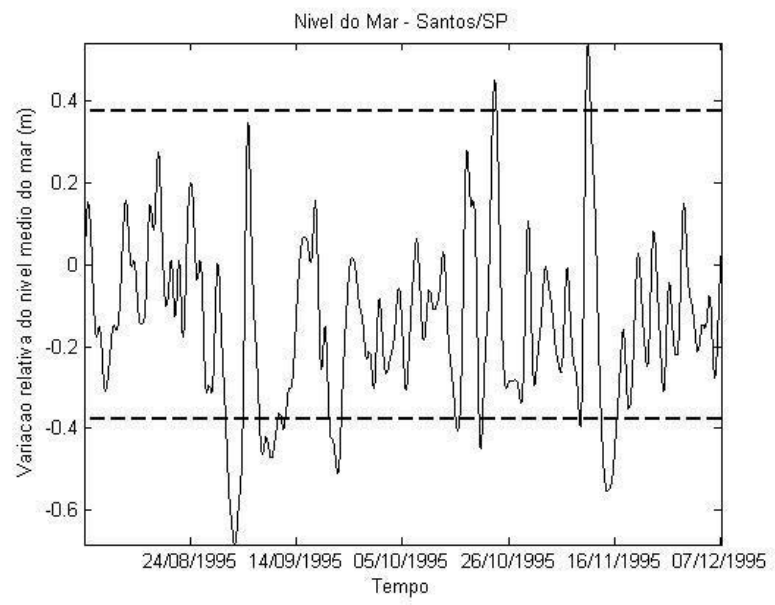

Figura 2 - Parte da série temporal da maré meteorológica e os limites de +2 e -2 desvios-padrão (nos níveis de $+0,38 \mathrm{~m}$ e $-0,38 \mathrm{~m}$ em tracejado). $\mathrm{Na}$ abscissa encontram-se os índices relativos ao tempo (em horas) e na ordenada o nível do mar filtrado (maré meteorológica, em centímetros).

Tabela 1 - Quantificação dos eventos superiores a +2 desvios padrão, considerando a série filtrada de valores diários de elevação do nível do mar.

\begin{tabular}{|c|c|c|c|c|c|}
\hline Acima de+2 d.p. & Primavera & Verão & Outono & Inverno & Total \\
\hline $1951-1960$ & 16 & 12 & 48 & 28 & 104 \\
\hline $1961-1970$ & 13 & 16 & 49 & 41 & 119 \\
\hline $1971-1980$ & 19 & 26 & 53 & 36 & 134 \\
\hline $1981-1990$ & 21 & 10 & 47 & 42 & 120 \\
\hline
\end{tabular}

Tabela 2 - Quantificação dos eventos inferiores a -2 desvios padrão, considerando a série filtrada de valores diários de elevação do nível do mar.

\begin{tabular}{|c|c|c|c|c|c|}
\hline Abaixo de -2 d.p. & Primavera & Verão & Outono & Inverno & Total \\
\hline $1951-1960$ & 30 & 6 & 10 & 26 & 72 \\
\hline $1961-1970$ & 17 & 6 & 2 & 27 & 52 \\
\hline $1971-1980$ & 45 & 9 & 7 & 14 & 75 \\
\hline $1981-1990$ & 35 & 7 & 8 & 20 & 70 \\
\hline
\end{tabular}


negativa e poucos de elevação positiva (47,2 \% e $14,5 \%$, respectivamente).

Uma maneira de sintetizar esses resultados de caráter sazonal, mas sem a divisão decadal, é através das curvas de ocorrência normalizada, conforme apresentado na Figura 3.

É possível observar no verão a distribuição concentrada em torno da maré meteorológica "zero" (ou seja, próxima do nível médio) e poucos casos extremos. Nota-se na Figura 3 a curva relativa a essa estação atingindo $14 \%$ de ocorrências próximo à maré meteorológica nula. Não obstante, nas curvas do outono e inverno sobressaem os limiares acima de 0,38 metros, com destaque na parte direita da Figura 3, enquanto que as curvas da primavera e inverno se destacam por possuírem maiores valores em intervalos abaixo de - 0,30 metros. Naturalmente, espera-se pouca ocorrência de eventos extremos no verão, representando apenas $10,4 \%$ do total de eventos extremos negativos e 13,4 $\%$ dos positivos. De maneira inversa, o inverno possui maior quantidade de casos, tanto positivos quanto negativos. O outono caracteriza-se com tendência a amplitudes positivas, com curva deslocada à direita do "zero", enquanto a primavera apresenta tendência a valores negativos e, portanto, curva deslocada à esquerda do nível médio ou o "zero" da Figura 3.

\subsection{Resultados dos Campos Sobrepostos de Pressão e Vento em Superfície para Eventos Extremos Pré- Selecionados (Composições)}

Esta representação visa identificar situações atmosféricas correspondentes aos extremos de nível do mar em Santos, através de uma representação gráfica conjunta dos campos de vento na superfície e da pressão ao nível do mar. A Figura 4 apresenta as composições sazonais médias para os casos de elevações negativas (menores que -2 desvios-padrão) para o período de 1951 a 1990.

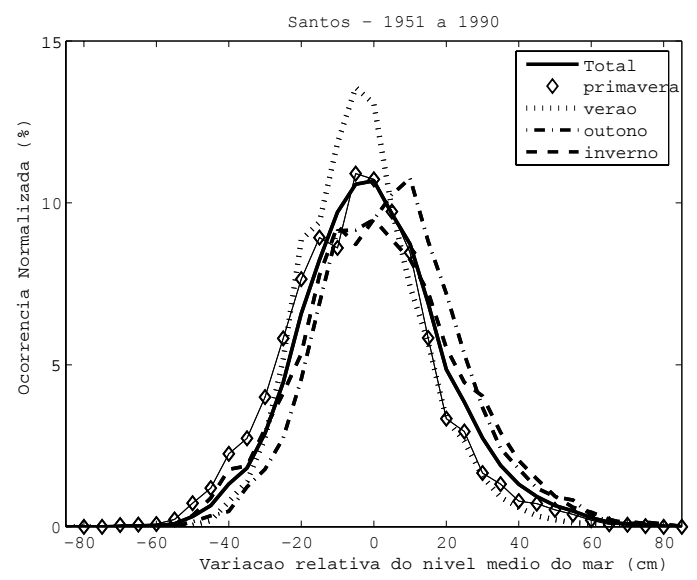

Resumidamente, as elevações ou abaixamentos do nível médio do mar respondem a dois processos: variação da pressão atmosférica e tensão do vento em superfície. O primeiro é chamado "efeito do barômetro invertido", conhecido por resultar em variações em torno de 1 centímetro a cada $1 \mathrm{hPa}$, ou seja, uma queda de pressão de $10 \mathrm{hPa}$ em superfície, por exemplo, resulta em aumento de 10 centímetros no nível do mar. O segundo fenômeno é explicado pela teoria de Ekman, que aborda as forças devido à tensão do vento paralelo à superfície oceânica. A extensão a que são sentidos em profundidades abaixo da superfície é determinada pelo tempo de ação e pela estratificação da densidade da coluna de água, que controla a transferência de momento (Pugh, 1987). A resultante do transporte da massa d'água, e conseqüente, o empilhamento em regiões de menor profundidade, ocorre à esquerda da direção do vento no Hemisfério Sul (Godin, 1972).

Normalmente, em uma tempestade particular, os efeitos do vento e da pressão atmosférica não podem ser identificados separadamente. Em situações associadas a sistemas meteorológicos extratropicais, considera-se a tensão do vento como principal forçante geradora dos distúrbios, uma vez que as pistas de vento são consideravelmente maiores e mais persistentes do que suas correspondentes na região tropical e sub-tropical. Desta forma, o empilhamento de água na costa é principalmente devido ao transporte de Ekman e não ao efeito do barômetro invertido.

Os ventos, que causam os casos negativos mostrados na Figura 4, são de leste-nordeste, confirmando a teoria de Ekman citada. $\mathrm{O}$ fator predominante para o abaixamento do nível do mar é a região de alta pressão, ou anticiclone, sobre o oceano. Esse se apresenta com maior intensidade no inverno, seguido pela primavera. Comparando as estações de transição, observa-se que a primavera tem a direção do vento com ângulo paralelo à costa,

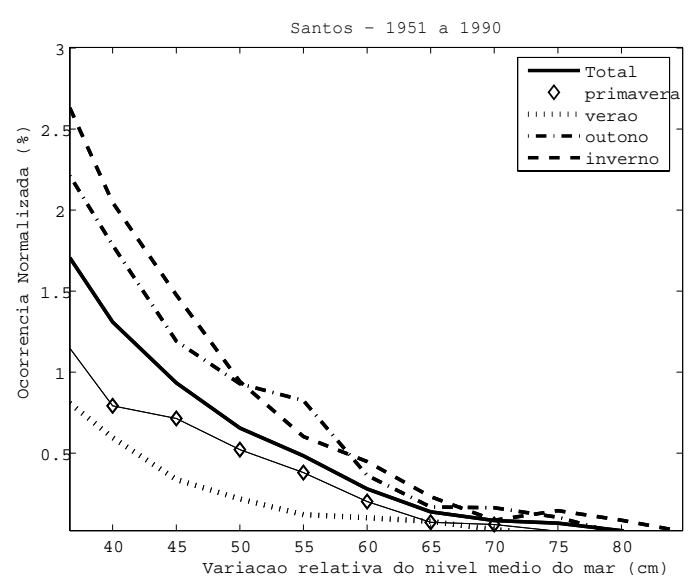

Figura 3 - Histogramas da série total e das séries sazonais para período de 1951 a 1990. A figura da direita enfoca os valores acima de +2 desviospadrão (acima de $+0,38 \mathrm{~m}$ ), típicos dos casos de ressaca. 
o que induz maior transporte de Ekman e grande abaixamento do nível do mar. Tal fato ocorre com o centro de alta pressão mais intenso sobre o oceano, aumentando o gradiente de pressão, e conseqüentemente, as intensidades dos ventos observados.

$\mathrm{Na}$ Figura 5 são apresentadas as composições sazonais médias para os casos de elevação positiva acima de +2 desviospadrão. Nesses casos são observados ventos intensos de sudoeste, com forte cavado sobre o oceano próximo ao litoral da região sudeste brasileira. O posicionamento da alta pressão da retaguarda, situada aproximadamente sobre o Uruguai, é fator predominante para a localização e intensificação do cavado sobre o oceano, gerando ventos de sudoeste em torno de $10 \mathrm{~m} / \mathrm{s} \mathrm{de} 40^{\circ}$ até $20^{\circ}$ Sul. No verão os centros são menos intensos e o cavado apresenta-se pouco pronunciado, com ventos moderados abaixo de $8 \mathrm{~m} / \mathrm{s}$. No inverno e nas estações de transição, os gradientes de pressão tornam-se mais intensos, aumentando a pista de sudoeste junto à costa, com ventos acima de $10 \mathrm{~m} / \mathrm{s}$, que provocam o
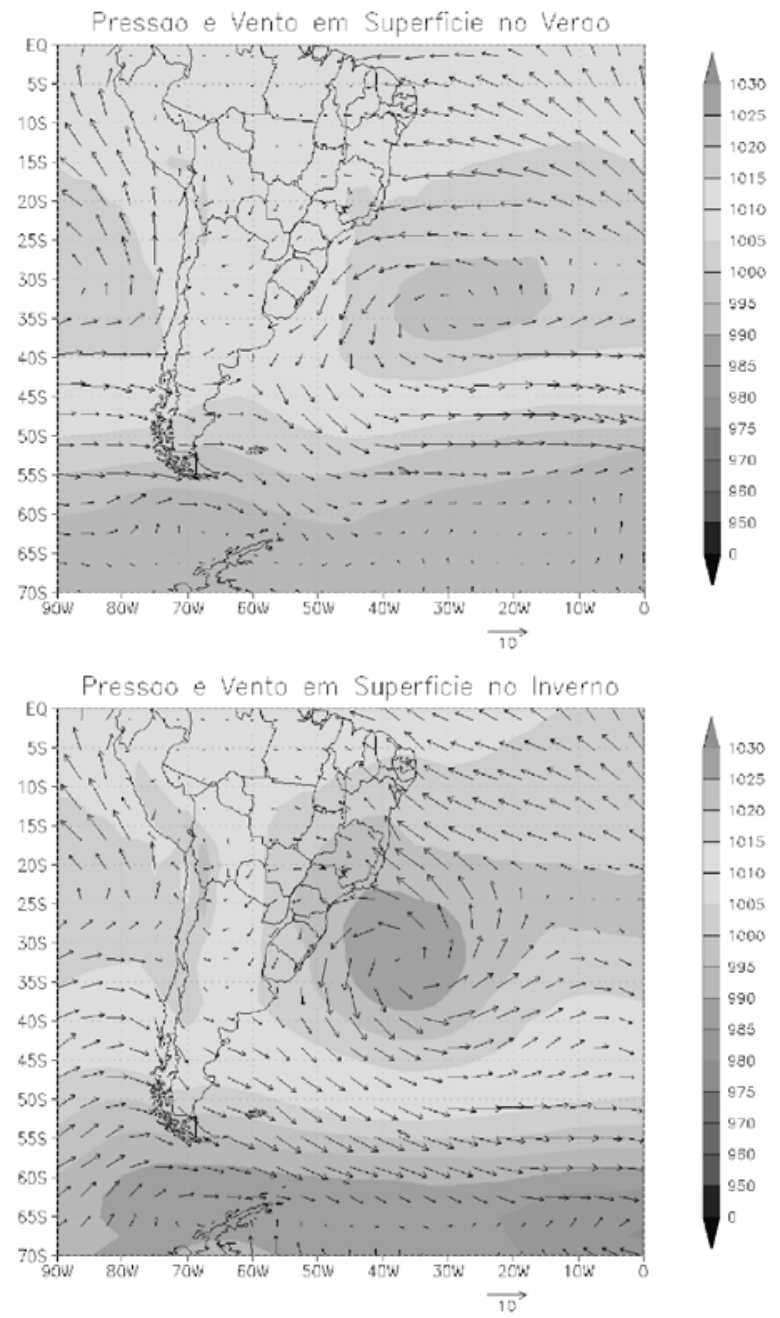

empilhamento de água e a sobre-elevação do nível do mar.

A identificação dos padrões, associados aos eventos negativos e positivos, fornece uma indicação clara do posicionamento dos centros de pressão atmosférica, permitindo inclusive uma distinção sazonal do comportamento. Ainda assim continua faltando o conhecimento do comportamento típico de evolução dos padrões meteorológicos. Para alcançar tal objetivo, foram elaboradas as composições relativas aos eventos mais extremos (elevações superiores a +3 desvios-padrão e inferiores a -3 desvios-padrão), enfocando agora sua evolução temporal nos dias que antecedem os eventos selecionados (Figura 6).

Percebe-se claramente a importância não só da intensificação e área de cada sistema, mas também da permanência de atuação, associada à velocidade de sua propagação. Os cavados e anticiclones, sobre o oceano, estão inseridos na circulação de oeste típica de médias latitudes. Alguns destes sistemas se originam em latitudes mais altas e
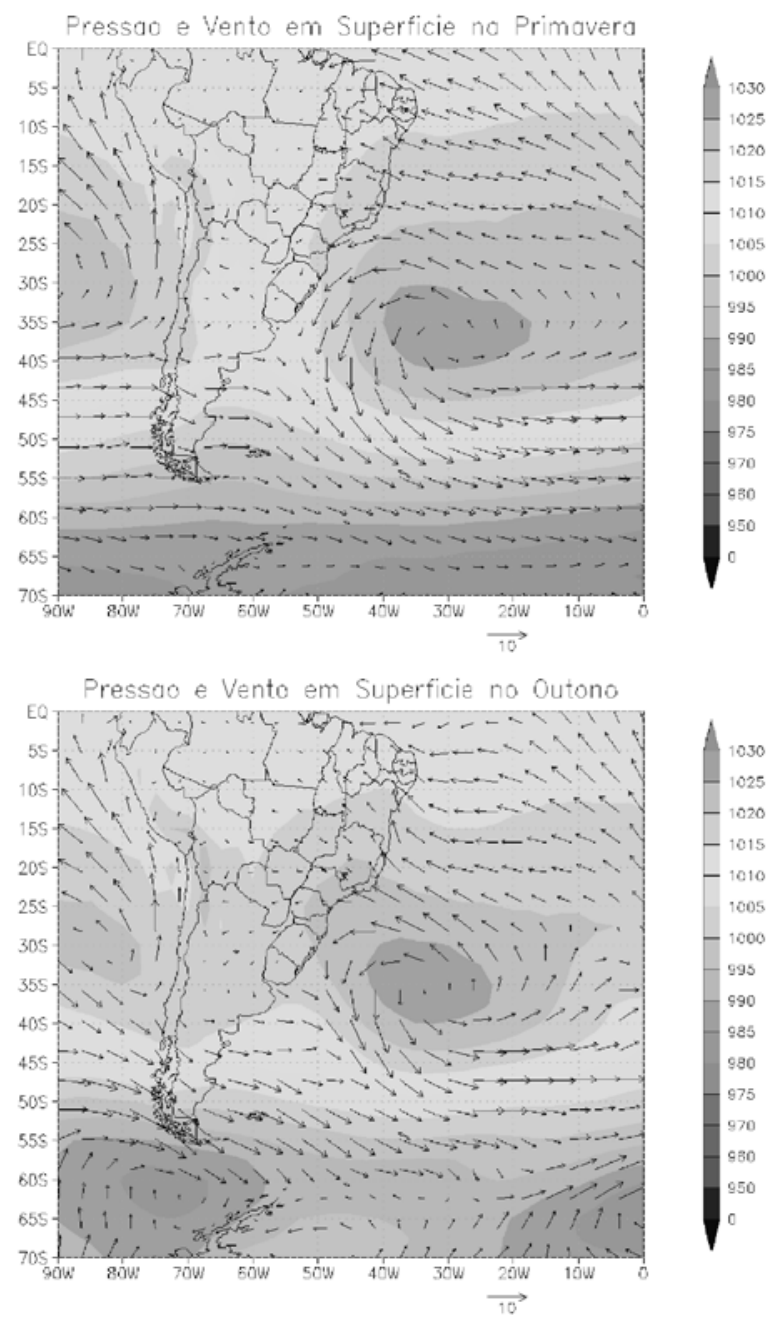

Figura 4 - Variação sazonal das composições para eventos inferiores a -2 desvios padrão. O campo sombreado refere-se à pressão ao nível do mar (escala de cinza, em $\mathrm{hPa}$ ) e os vetores representam o vento na superfície (em m/s): verão (superior esquerdo), outono (superior direito), inverno (inferior esquerdo) e primavera (inferior direito). 
propagam junto ao litoral, mantendo intensidade e persistência. Tais fatores, combinados à incidência de sudoeste para nordeste (paralelo à linha de costa) dos ventos, induzem o surgimento de ondas de plataforma, que se propagam e atingem primeiro a região sul brasileira, evoluindo para São Paulo e Rio de Janeiro (Castro e Lee, 1995). Os fenômenos não são espacialmente nem temporalmente independentes, já que um evento extremo ao sul permite antever o que vem a ocorrer mais ao norte. O mesmo pode ser notado quanto à intensidade positiva ou negativa da elevação, onde os eventos negativos antecedem os extremos positivos, com as passagens de centros de alta pressão e entradas de frentes frias causando as ressacas.

\section{CONCLUSÃO}

Foram observadas variações interdecadais pequenas nas ocorrências dos eventos extremos distribuídos ao longo das
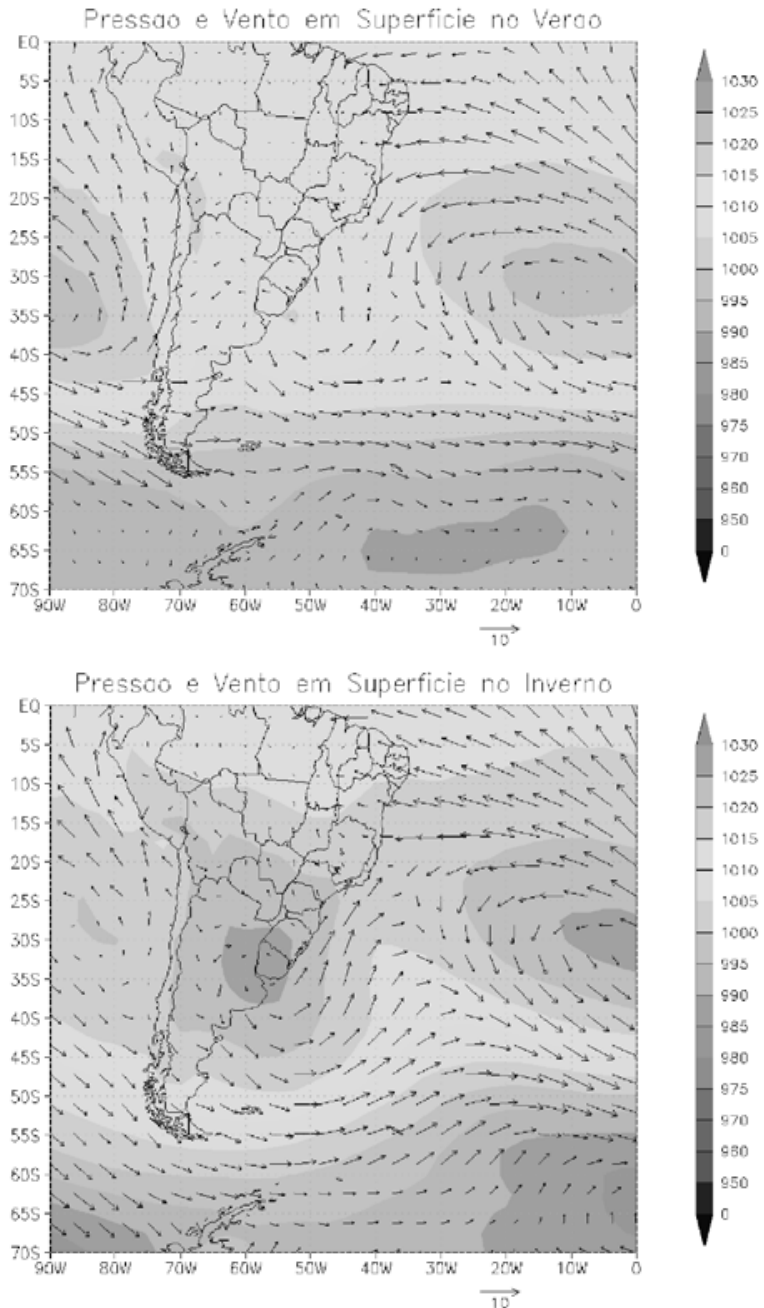

estações. No inverno foi encontrado grande número de variações, tanto positivas quanto negativas da maré meteorológica, caracterizando grande dispersão entre os eventos. No outono há uma tendência de maior concentração de extremos positivos e na primavera negativos, padrões que se mantém ao longo das décadas estudadas. Dessa forma, pode-se dizer que as flutuações de escala sinótica associadas a condições específicas possuem um comportamento típico, as quais apresentam pouca variação ao longo dos anos, conforme evidenciado nas tabelas de quantificação de ocorrências (Tabelas 1 e 2). Há pequenas variações também no total de casos ao comparar as décadas consideradas, com tendência ao aumento do número de extremos positivos de 1951 a 1980. No caso de extremos negativos, os totais são em torno de 70 casos, com exceção da década 1961-1970, com apenas 52. Em termos percentuais, as variações interdecadais do total de eventos positivos estão em $13 \%$, enquanto as variações negativas $23 \%$. Considerando todo
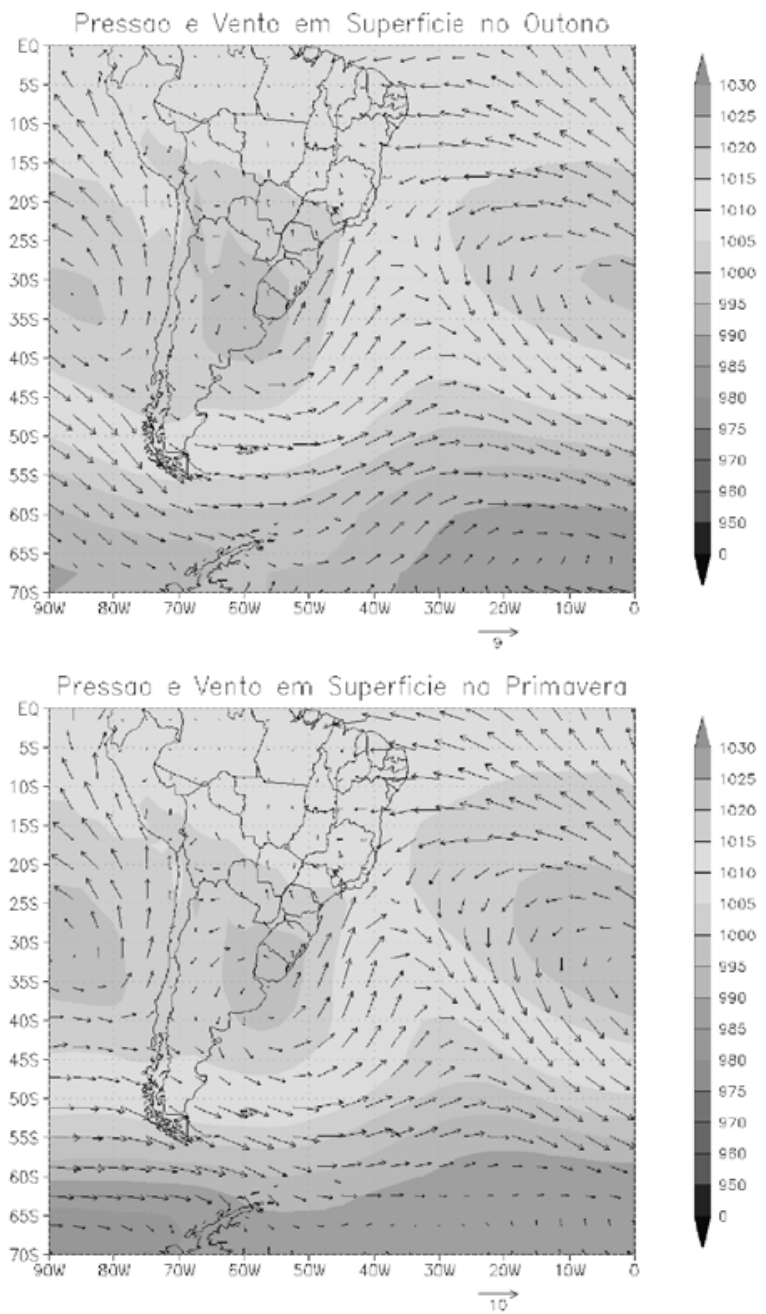

Figura 5 - Variação sazonal das composições para eventos superiores a +2 desvios padrão. $\mathrm{O}$ campo sombreado refere-se à pressão ao nível do mar (escala de cinza, em hPa) e os vetores representam o vento na superfície (em m/s): verão (superior esquerdo), outono (superior direito), inverno (inferior esquerdo) e primavera (inferior direito). 

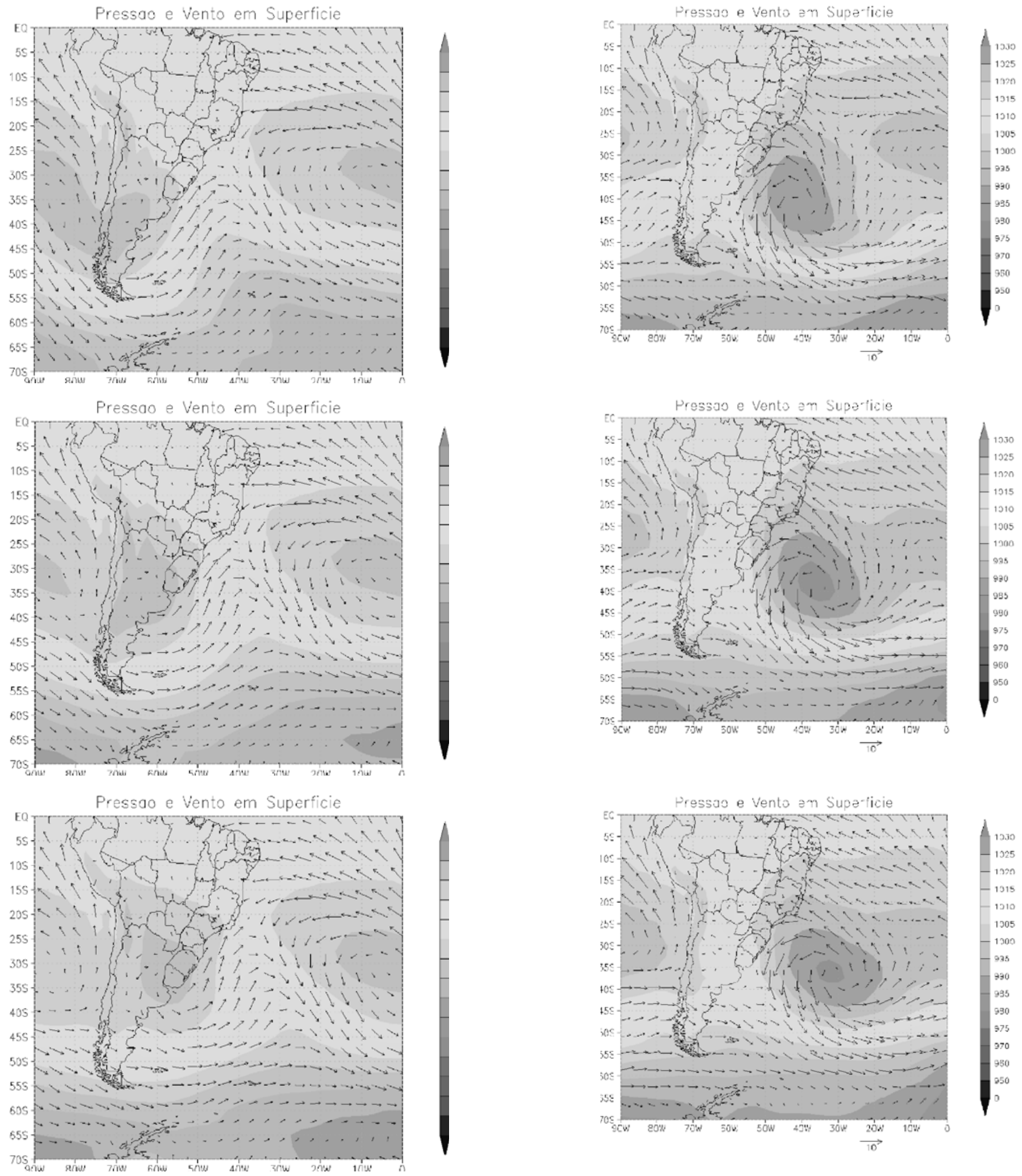

Figura 6 - Evolução temporal das composições para eventos superiores e inferiores a +3 e -3 desvios padrão, no período 1951-1990. O campo sombreado refere-se à pressão ao nível do mar (escala de cinza, em hPa) e os vetores representam o vento na superfície (em $\mathrm{m} / \mathrm{s}$ ). Eventos positivos no lado esquerdo e negativos no direito, sendo o superior referente a dois dias antes, o intermediário ao dia anterior e o inferior ao dia do evento. 
o período analisado, chega-se a média anual de 12 eventos de maré meteorológica acima de $+0,38$ metros, e 7 eventos de maré meteorológica abaixo de - 0,38 metros.

A explicação do grande número de eventos negativos da primavera, observado na Tabela 2, se deve ao fato dos meses de agosto e setembro serem característicos de ocorrência de sistemas de bloqueio sobre o Oceano Atlântico Sul (Casarin, 1983), induzindo tipicamente ventos de nordeste sobre o litoral associados a cavados sobre o continente, com a consequente queda do nível do mar. No outono esse padrão não é freqüente, sendo um período de forte ciclogênese e intensificação de sistemas de baixa pressão sobre o oceano, conforme apresentado por Gan e Rao (1991) e Reboita (2008), com ventos de sudoeste que elevam o nível do mar no litoral sudeste, justificando os poucos casos de marés meteorológicas negativas.

A observação dos campos de pressão e vento (composições) tem a função de identificar espacialmente padrões médios, que justificam os argumentos acima apresentados. Assim como nas tabelas e curvas de distribuição, as composições também se apresentam de maneira muito semelhante nas décadas consideradas. Nos casos de elevações positivas, destaca-se a dependência dos extremos com a intensificação, o tamanho e o posicionamento dos cavados sobre o oceano. No inverno e outono, época com grande ocorrência de elevações positivas do nível do mar, é possível observar os ventos de sudoeste intensos, aproximadamente paralelos à costa, abrangendo regiões extensas e próximas ao litoral; padrão esse determinado pelos cavados sobre o oceano em conjunto com a alta pressão sobre o continente. No verão e primavera ocorre o enfraquecimento dos cavados, com perda de vorticidade e diminuição das intensidades dos ventos, sendo então os casos de inundação menos freqüentes. Merece destaque a grande intensificação do anticiclone sobre o continente no inverno, aumentando os gradientes de pressão, responsáveis pelos intensos ventos de sudoeste citados, provando ser o período de maior incidência de casos extremos.

Analisando a sazonalidade de eventos negativos, observam-se o inverno e a primavera como os períodos de máxima intensidade das altas pressões sobre o oceano, conseqüência do aumento do número e da permanência de bloqueios, conforme citado. $\mathrm{O}$ posicionamento e a intensidade são diferentes entre as duas estações, sendo que no inverno o centro de alta pressão se encontra, em média, mais ao norte com maior intensidade, enquanto na primavera mais ao sul e menos intenso. No outono e principalmente no verão, em geral, não se formam grandes pistas com ventos de nordeste a ponto de gerar casos importantes de maré meteorológica negativa.

De acordo com a teoria, uma pista de geração de onda de maré meteorológica depende da intensidade do vento (aproximadamente paralelo à costa), área de atuação, permanência e da batimetria local (Pugh, 1987). Ou seja, é fundamental para a ocorrência de inundações, com elevação do nível do oceano, que as condições citadas nos itens anteriores se mantenham por um período da ordem de dias. Em relação à intensidade, foi observado em média, que os extremos positivos estão associados a pistas com ventos acima de $8 \mathrm{~m} / \mathrm{s}$ sobre o oceano próximo à costa.

Acompanhando a evolução temporal dos quadros sinóticos nos períodos extremos de elevações positivas do nível do mar, apresentada na Figura 6, observa-se o cavado bem determinado dois dias antes do evento máximo detectado, com gradientes e ventos já bastante intensos, eixo um pouco mais a oeste e deslocado para o sul. Nesse mesmo dia, no litoral de São Paulo e Rio de Janeiro, os ventos são de nordeste com maré meteorológica negativa. Já a costa da Argentina, do Uruguai e do Estado do Rio Grande do Sul recebem a influência da pista de sudoeste, gerando maré meteorológica positiva, a qual se propaga e atinge Santos nos dias subseqüentes, corroborando com algumas sugestões apresentadas por Castro e Lee (1995).

No dia que antecede o evento, observa-se o deslocamento dos cavados para leste, acompanhando a circulação de oeste típica dessa latitude, ganhando intensidade. É possível notar que as frentes frias associadas, as quais propagam para nordeste, se encontram sobre o Paraná e São Paulo dois dias antes do evento, passando pelo Rio de Janeiro no dia anterior e sobre o norte do Espírito Santo no dia do máximo de elevação em Santos. No instante em que ocorre o extremo de maré meteorológica a frente já havia passado por Santos entre um e dois dias.

A condição mais propícia para a ocorrência de um evento superior a 3 desvios-padrão (0,57 metros), se encontra na persistência dos sistemas nos dias anteriores ao evento em si, deixando claro o papel da intensificação do padrão de onda vinda do sul ao longo do tempo. É possível afirmar, portanto, que fenômenos extremos envolvendo nível do mar não tendem a ocorrer com forçantes locais próximas a Santos, mas dependem da evolução temporal e persistência da pista de vento de sudoeste ao longo de toda a costa sul-sudeste brasileira.

\section{REFERÊNCIAS BIBLIOGRÁFICAS}

BUTLER, A.; HEFFERNAN, J. E.; TAWN, J. A.; FLATHER, R. A.; HORSBURGH, K. J. Extreme value analysis of decadal variations in storm surge elevations. Journal of Marine Systems, v. 67, p. 189 - 200, 2007.

CAMARGO, R; HARARI, J. Modelagem numérica de ressacas na plataforma sudeste do Brasil a partir de cartas sinóticas de pressão atmosférica na superfície. Bolm Inst. Oceanogr., S Paulo, v. 42(1), p.19-34, 1994. 
CASARIN, D.P. Um estudo observacional sobre os sistemas de bloqueio no Hemisfério Sul. Dissertação de Mestrado, INPE, 1983.

CASTRO, B.M.; LEE, T.N. Wind-forced sea level variability on the southeast Brazilian shelf. Journal of Geophysical Research, v. 100, n C8, p. 16,045-16,056, August 15, 1995.

DONG, S.; FU, X.; SANG, S. Extreme Negative Storm Surge Analysis in Shallow Water Area. Proceedings of The Seventh ISOPE Pacific/Asia Offshore Mechanics Symposium. Dalian, China, September 17-21, 2006.

FIORE, M. M. E.; D'ONOFRIO, E. E.; POUSA, J. L. Storm surges and coastal impacts at Mar del Plata, Argentina. Continental Shelf Research, ISSN 02784343, 2009.

GAN , M.A.; RAO, B.V. Surface cyclogenesis over South America. Mon. Wea. Rev., v. 119, p. 293-302, 1991.

GODIN, G. The Analysis of Tides. Univ Toronto Press, Buffalo, 1972, p.264.

HARARI, J.; CAMARGO, R. Simulação da propagação das nove principais componentes de maré na plataforma sudeste brasileira através de modelo numérico hidrodinâmico. Bolm Inst. Oceanogr., S Paulo, v. 42(1), p. 35-54, 1994.

KALNAY, E.; KANAMITSU, M.; KISTLER, R.; COLLINS, W.; DEAVEN, D.; GANDIN, L.; IREDELL, M.; SAHA, S.; WHITE, G.; WOOLLEN, J.; ZHU, Y.; CHELLAH, M.; EBISUZAKI, W.; HIGGINS, W.; JANOWIAK, J.; MO, K. C.; ROPELEWSKI, C.; WANG, J.; LEETMAA, A.; REYNOLDS, R; JENNE, R; JOSEPH, D. The NCEP/NCAR 40-Year Reanalysis Project. Bull. Amer. Meteor. Soc., v. 77, p. 437-471, 1996.

MARONE, E.; CAMARGO, R. Marés meteorológicas no litoral do estado do Paraná: o evento de 18 de Agosto de 1993, Nerítica, Cuririba, v.8(1-2), Editora da UFPR, p.7385, 1994.
OLIVEIRA, M. M. F.; EBECKEN, N. F. F.; SANTOS, I. A.; NEVES, C. F.; CALOBA, L. P.; OLIVEIRA, J. L. F. Modelagem da Maré Meteorológica Utilizando Redes Neurais Artificiais: Uma Aplicação para a Baía de Paranaguá - PR, Parte1: Dados Meteorológicos da Estação de Superfície. Revista Brasileira de Meteorologia, v.21, n.2, p. 220-231, 2006.

PENG, M.; XIE, L.; PIETRAFESA, L. J. A numerical study on hurricane-induced storm surge and inundation in Charleston Harbor, South Carolina. Journal of Geophysical Research, v. 111, 2006.

PORE, N. A. The Relation of Wind and Pressure to Extratropical Storm Surges at Atlantic City. Journal of Applied Meteorology, v. 3, Issue 2 (April 1964), p. 155-163, 1964.

PUGH, D. T., Tides, Surges and Mean Sea Level. Great Britain: John Wiley \& Sons, 1987, 472 p.

RAICICH, F. Recent evolution of sea-level extremes at Trieste (Northern Adriatic). Continental Shelf Research, v. 23, p. 225-235, 2003.

REBOITA, M. S., Ciclones Extratropicais sobre o Atlântico Sul: Simulação Climática e Experimentos de Sensibilidade. Tese de Doutoramento, IAG-USP, São Paulo, SP, Brasil, 2008.

STECH, J. L.; LORENZZETTI, J. A. The Response of the South Brazil bight to the passage of wintertime cold fronts, Journal of Geophysical Research, v. 97, NO. C6, p.95079520, 1992.

ULLMANN, A.; PIRAZZOLI, P.A.; TOMASIN, A. Sea surges in Camargue: Trends over the 20th century. Continental Shelf Research, v. 27, p. 922-934, 2007. 